\title{
Consumerism in prenatal diagnosis: a challenge for ethical guidelines
}

Wolfram Henn Saarland University, Homburg/Saar, Germany

\begin{abstract}
The ethical guidelines for prenatal diagnosis proposed by the World Health Organisation (WHO), as well as by national regulations, only refer to paternity and gender of the fetus as unacceptable, disease-unrelated criteria for prenatal selection, as no other such parameters are at hand so far. This perspective is too narrow because research on complex genetic systems such as cognition and ageing is about to provide clinically applicable tests for genetic constituents of potentially desirable properties such as intelligence or longevity which could be misused as parameters for prenatal diagnosis. Moreover, there is an increasing number of prenatally testable genetic traits, such as heritable deafness, which are generally regarded as pathological but desired by some prospective parents and taken into account as parameters for pro-disability selection. To protect prenatal diagnosis from ethically unacceptable genetic consumerism, guidelines must be clarified as soon as possible and updated towards a worldwide restriction of prenatal genetic testing to immediately disease-determining traits.

(Fournal of Medical Ethics 2000;26:444-446)
\end{abstract}

Keywords: Genetics; prenatal diagnosis; ethics; consumerism

Prenatal diagnosis is one of the ethically most problematic applications of genetics, at least as far as it is aimed at conditions which, if detected in the fetus, are incurable and thus may lead to selective abortion. In particular, prenatal diagnosis of genetic traits typically can only provide information to assist the prospective parents in their decision making whether to carry the pregnancy to term or to terminate it.

It is generally accepted that any prenatal diagnosis requires both a medical indication and informed consent of the parents. Consequently, parents have a right to refuse medically indicated prenatal diagnosis even if there is a high risk for a fetal condition that is incompatible with life, for example if a parent is a balanced carrier of a lethal chromosome aberration such as trisomy 13 . On the other hand, there are a few genetic traits, namely the gender of the fetus and paternity, which are accessible to prenatal diagnosis today but unrelated to health. Thus, by the majority of geneticists throughout the world, they are not regarded as reasonable parameters on which an abortion could depend. ${ }^{1}$
In 1998, the World Health Organisation proposed guidelines on ethical issues in medical genetics in which that issue is addressed:

"Prenatal diagnosis is carried out only to give parents and physicians information about the health of the fetus. The use of prenatal diagnosis for paternity testing, except in cases of rape or incest, or for gender selection, apart from sex-linked disorders, is not acceptable". ${ }^{2}$

This guideline is a remarkable achievement as it documents unanimous ethical accordance between representatives of such different sociocultural backgrounds as Western and Eastern Europe, China, India, and the Islamic countries. Paternity and gender are the only explicitly mentioned parameters of prenatal diagnosis that are of potential interest for parents but unrelated to health and therefore regarded as ethically unacceptable, as they are today's only routinely testable genetic properties of this kind. Desirable but so far not included in the WHO guidelines is the exclusion of heterozygosity testing for recessive diseases from prenatal diagnosis, as is done in the Germanspeaking countries. ${ }^{3}$ Although heterozygosity testing, that is, the search for a hidden disease carrier status, is aimed at disease-relevant traits such as cystic fibrosis or Tay-Sachs disease, the heterozygous carrier state of a fetus is insignificant for his or her future individual wellbeing but only, under certain conditions, for the following generation. Thus, heterozygosity testing in the context of prenatal diagnosis could, if at all, only be attempted for eugenic purposes. Even then, it would make little sense because of the high frequency of healthy heterozygotes for recessive diseases within the general population in any country.

\section{Novel parameters for prenatal selection}

At its present state of methodology, prenatal genetic diagnosis is restricted to the identification of either microscopically visible chromosome aberrations or, at the molecular scale, mutations within one, at maximum a few, single genes of interest. The exclusive targets of prenatal molecular genetic diagnosis so far have been genes responsible for monogenic diseases. The identification of genetic determinants of desirable properties appeared out of reach and, consequently, perhaps not worth regulating. The reason for this confinement to disease-relevant traits is the fact that genetically determined or influenced desirable phenotypes, for 
example intelligence, typically require a puzzling cooperation of numerous relevant genes plus environmental factors. On the other hand, the malfunction of a single essential gene can cause a distinctive pathological phenotype, that is, a monogenic disease such as phenylketonuria, which alone outweighs the effect of all other intelligencedetermining genes and causes mental retardation. These simple genotype-phenotype relationships have, until recently, favoured monogenic diseases as targets of genetic analysis.

Conversely, genetic factors that can positively influence complex non-pathological phenotypes were known to exist-think of the never-ending nature $\mathrm{v}$ nurture discussion on intelligence ${ }^{4}$ - but were unidentifiable in the form of testable variants of specific genes. As a consequence, the discussion on the systematic abuse of genetic diagnosis was focused on negative rather than positive eugenics in the absence of measurable parameters for the latter. ${ }^{5}$

But this is about to change; the age of positive eugenics is almost upon us.

Modern strategies of genome analysis such as large scale DNA sequencing ${ }^{6}$ and multiplex gene expression analysis with DNA chips ${ }^{7}$ have provided powerful methods for elucidating the functional variations of multiple interacting genes as they are involved in quantitative genetic traits. In other words, genetic research is about to find the genetic needles in the haystacks of complex human properties such as longevity, body shape, or intelligence.

A few examples from basic resarch:

A mutation in the gene coding for the p66shc protein induces resistance to oxidative stress at the cellular level, resulting in a $30 \%$ increase in life span in mice. ${ }^{8}$

Variations of the gene for the angiotensinconverting enzyme have been shown to influence the muscle performance of humans, as demonstrated in army recruits. ${ }^{9}$

DNA samples from children with extremely high general cognitive ability $(g)$ showed a significant association to genomic loci on chromosome 4 as compared with DNA from children with average $g$, indicating that as yet unidentified intelligence-relevant genes may reside here. ${ }^{10}$

In a recent paper entitled Genetics and general cognitive ability, ${ }^{11}$ Robert Plomin predicts that "most of the heritability of $g$ will be accounted for eventually by specific genes, even if hundreds of genes are needed to do it". From the technical viewpoint, such multiplicity of genetic parameters within complex traits does not preclude genetic analysis any more, since DNA chips are available as ideal instruments for multiplex genetic testing. ${ }^{12}{ }^{13}$ To me, there is little doubt that this methodology will soon give access to the genetic factors within $g$ and other complex multifactorial traits and allow a probabilistic, although not accurate prediction of a child's potential that may well interest some parents-to-be. Plomin asks: "Is it possible that there are parents who would use DNA chips for $g$ prenatally for eugenic purposes?" And answers that such "expensive high-tech genetic engineering in regard to behavioural traits is unlikely to happen for a long time". ${ }^{11}$

I do hope that he will turn out to be right, but several studies on the attitudes of the general population as well as of geneticists towards prenatal selection give the impression that consumerism will prevail. A significant proportion of the public in developed as well as developing countries is in favour of allowing prenatal diagnosis and selective termination for conditions such as two missing fingers, short stature, obesity, or even limited musical talent. ${ }^{14-16}$ Statements of genetics professionals indicate that requests for such medically more or less irrelevant prenatal selection parameters, if available, are likely to be met. In a survey of geneticists in 37 nations, Dorothy Wertz and John Fletcher report that more than a quarter of geneticists in Western countries would be ready to perform prenatal diagnosis for sex selection, with, moreover, eight per cent, arguing that "patients have a right to whatever service they can pay for". ${ }^{17}$ Most strikingly, the authors note a worldwide increase in willingness to accede to requests for sex selection over the last decade, with a compliant attitude most common among professionals of younger age.

\section{Are we prepared?}

Could there be any reasonable doubt that a DNA chip or other testing device that promised parentsto-be a better chance-although no guarantee - of a tall, slim, bright child would be excellently marketable? I feel that this idea is incompatible with the fundamental principle of nil nocere. To accept or even promote such unethical ways of parental choice would mean to surrender medical genetics to free-market eugenics. Therefore, there is an urgent need to extend the current ban on prenatal paternity and gender testing to any parameter of prenatal genetic diagnosis that is not immediately related to severe disease in the prospective child. Such a general anti-abuse clause would also fill another gap in ethical guidelines for prenatal diagnosis that is opening in the context of the ongoing identification of disability-determining genes: the as yet unregulated option of prenatal selection in favour of traits that are generally regarded as pathological but may be desired by some prospective parents.

A significant proportion of deaf parents would prefer to have deaf children, and some of these would be ready to consider having prenatal diagnosis in order to terminate a pregnancy with a fetus expected to be hearing. ${ }^{18}$ The same situation may apply for couples affected with, but not suffering from, heritable forms of short stature, visual impairment, and so on. The as yet limited knowledge about the genetic basis of most hereditary disabilities has prevented pro-disability selection from becoming a practically relevant issue. For instance, over thirty genes for hereditary 
deafness are known to exist, only few of which are accessible for molecular diagnosis so far. ${ }^{19}$ But here again, the ongoing mapping of the human genome and the forthcoming development of multiplex DNA assays for the simultaneous investigation of many if not all disease-relevant gene ${ }^{20}$ will inevitably put the matter on the agenda of applied medical ethics.

It is beyond the scope of this paper to discuss in depth whether the "choice to have a disabled child" ${ }^{21}$ actually warrants a legitimate request for prenatal testing. At least it may be said that terminating a pregnancy because the baby will be healthy in a way that most people, but not his or her parents, understand it, is counterintuitive to the Hippocratic ideas of health care.

The abuse of genetic testing for prenatal gender selection has already become a major societal problem in several countries. ${ }^{22} 23$ Now, in the age of the commercialisation of human genetics, it would be naive to think that more sophisticated new opportunities of prenatal choice would not operate according to supply and demand in the future. Therefore, an unregulated approach to new technologies of prenatal testing will fail to draw necessary ethical boundaries as there is no stable ethical consensus to safeguard the well established but endangered confinement of prenatal diagnosis to severe disease of the fetus.

A statutory approach, that is, a general ban on prenatal genetic diagnosis for any but immediately disease-determining traits, would not only clarify the issue for prenatal selection through abortion, but could also prospectively foreclose avenues of further research. ${ }^{24}$ Otherwise, the technically more demanding but logical next step towards freemarket eugenics might be to apply the new genetic criteria for prenatal choice to preimplantation diagnosis. ${ }^{25}$ Unlike prenatal diagnosis, pre-implantation diagnosis does not involve abortion which, as a traumatic intervention, provides a psychological barrier to parental choice relating to minor undesired traits. This is why selection through preimplantation diagnosis could become more sought after by prospective parents than through prenatal diagnosis. Ultimately, perhaps, even the wish for genetic enhancement via gene transfer, which has recently been shown to work in mice, might be extended to humans. ${ }^{26}{ }^{27}$

It may be too early to warn that we are at the edge of a slippery slope towards a new dimension of eugenics, but we must realise that new tools to fulfil the tempting wish to have not only healthy, but gifted children will soon be in our hands. It is an urgent task for legislators concerned with medical ethics to face that challenge and to define internationally consistent ethical boundaries for genetic consumerism. The WHO should take the first step by updating its guidelines on ethical issues in human genetics, ${ }^{2}$ putting an unmistakable ban on any kind of prenatal selection without medical justification.
Wolfram Henn, MD, is Consultant Clinical Geneticist and Lecturer in Human Genetics at the Institute of Human Genetics, Saarland University, Homburg/ Saar, Germany.

\section{References}

1 Wertz DC, Fletcher JC. Ethics and human genetics: a cross-cultural perspective. Heidelberg: Springer, 1989.

2 World Health Organisation. Proposed international guidelines on ethical issues in medical genetics and genetic services. Geneva: WHO, 1998

3 Committee for Public Relations and Ethical Issues of the German Society of Human Genetics. Position paper of the German Society of Human Genetics. Munich: Deutsche Gesellschaft für Society of Human Genet

4 Plomin R, DeFries JC. The genetics of cognitive abilities and disabilities. Scientific American 1998;278:62-9.

5 Wikler D. Can we learn from eugenics? Fournal of Medical Eth-

ics 1999;25:183-94.
6 Venter JC, Adams MD, Sutton GG, Kerlavage AR, Smith HO, Venter JC, Adams MD, Sutton GG, Kerlavage AR, Smith HO,
Hunkapiller M. Shotgun sequencing of the human genome.

Science 1998;280:1540-2.

7 Schena M.Genome analysis with gene expression microarrays. Bioessays 1996;18:427-31

8 Migliaccio E, Giorgio E, Mele S, Pelicci G, Reboldi P, Pandolfi $\mathrm{PP}$, et al. The p66shc adaptor protein controls oxidative stress response and life span in mammals. Nature 1999;402:309-13.

9 Williams AG, Rayson MP, Jubb M, World M, Woods DR, Hayward $\mathrm{M}$, et al. The ACE gene and muscle performance. Nature 2000;403:614.

10 Fisher PJ, Turic D, Williams NM, McGuffin P, Asherson P, Ball D, et al. DNA pooling identifies OTLs on chromosome 4 for general cognitive ability in children. Human Molecular Genetics 1999;8:915-22.

11 Plomin R. Genetics and general cognitive ability. Nature 1999; 402(suppl): C25-C29.

12 McKenzie SE, Mansfield E, Rappaport E, Surrey S, Fortina P Parallel molecular genetic analysis. European fournal of Human Genetics 1998;6:417-29.

13 Henn W. Genetic screening with the DNA chip: a new Pandora's box? fournal of Medical Ethics 1999;25:200-3.

14 Michie S, Drake H, Bobrow M, Marteau T. A comparison of public and professionals' attitudes towards genetic developments. Public Understanding of Science 1995:4:243-53.

15 Nippert I, Horst J. Die Anwendungsproblematik der pränatalen Diagnose aus der Sicht von Beratenen und Beratern. Bonn: TABHintergrundpapier $\mathrm{Nr} 2,1994$.

16 Milner KK, Collins EE, Connor GR, Petty EM. Attitudes of young adults to prenatal screening and genetic correction for human attributes and psychiatric conditions. American fournal of Medical Genetics 1998;76:111-19.

17 Wertz DC, Fletcher JC. Ethical and social issues in prenatal sex selection: a survey of geneticists in 37 nations. Social Science and Medicine 1998;46:255-73.

18 Middleton A, Hewison J, Mueller RF. Attitudes of deaf adults toward genetic testing for hereditary deafness. American fournal of Human Genetics 1998;63:1175-80.

19 Kalatzis V, Petit C. The fundamental and medical impacts of recent progress in research on hereditary hearing loss. Human Molecular Genetics 1998;7:1589-97.

20 Fodor SPA. Massively parallel genomics. Science 1997;277: 393-5

21 Michie S, Marteau TM. The choice to have a disabled child. American fournal of Human Genetics 1999;65:1204-7.

22 Calaça C, Akin A. The issue of sex selection in Turkey. Human Reproduction 1995;10:1631-2.

23 Mao X, Wertz DC. China's genetic sevices providers' attitudes towards several ethical issues: a cross-cultural survey. Clinical Genetics 1997;52:100-9

24 Knoppers BM, Hirtle M, Glass KC. Commercialization of genetic research and public policy. Science 1999;286:2277-8.

25 King D. Preimplantation genetic diagnosis and the "new" King D. Preimplantation genetic diagnosis and

26 Tang YP, Shimizu E, Dube GR, Rampon C, Kerchner GA, Zhuo M, et al. Genetic enhancement of learning and memory Zhuo M, et al. Genetic enhance
in mice. Nature 1999;401:63-9.

27 Gordon JW. Genetic enhancement in humans. Science 1999; 283:2023-4. 